\title{
Oral Reading Intervention for an English Language Learner: A Single-case Design
}

\author{
Hui Hong Gan \\ University Malaysia Sarawak, Kota Samarahan, Malaysia \\ Julia Ai Cheng Lee \\ University Malaysia Sarawak, Kota Samarahan, Malaysia \\ Kartini Abdul Ghani \\ University Malaysia Sarawak, Kota Samarahan, Malaysia
}

\begin{abstract}
The purpose of this paper was to investigate the effectiveness of conducting a reading intervention in a public primary school setting in Chinese vernacular school in Malaysia. Literature indicated that struggling readers did not master letter-sound correspondences despite the phonics was emphasised in to date curriculum. One male learner who was identified by his classroom teacher as needing special assistance in reading performance participated this research. Using a single-case research design, the participant's oral reading fluency (ORF) in terms of word correct per minute (WCPM) was measured. Several nonparametric statistics methods, such as Tau and percentage of nonoverlapping data (PND) were applied to compute the degree of association and effectiveness of the intervention, respectively. Visual analysis was carried out to interpret the graph. The data collected was also compared with the updated ORF norm that was established in the United States. The results revealed that the reading intervention facilitated the improvement of ORF of the participant. The significant implications and future research recommendations on the development of reading intervention were highlighted.
\end{abstract}

Index Terms — reading difficulties, phonics, oral reading fluency, single-case research design

\section{INTRODUCTION}

The Ministry of Education in Malaysia has implemented the Standardized Curriculum for Primary School (KSSR) with the goal of fostering learners' phonics in standard British English starting from Primary One (Ali, Hamid \& Moni, 2012). However, there are learners still struggling to master the phonics to read (Su \& Hawkins, 2013). Regardless to the sociolinguistic background of the learners, all of them learn English language as a second language (ESL) compulsorily in Malaysian public schools. Educators (Chitravelu, Sithamparam \& Teh, 2005) reported the common pattern of oral reading problems that the Malaysian ESL learners encountered according to their ethnicities and their first language (L1; see examples Chitravelu et al., 2005). The negative interference from the L1 happens among the Malaysian ESL learners during English oral reading because of the lack of familiarity with their second language (L2; Khor, Low, \& Lee, 2014; Pillai \& Paramasivam, 2014). It is not an unusual phenomenon for ESL learners to get confused between languages in Malaysia.

Scholars defined struggling readers are those having problems to translate the printed or handwritten words (visual stimuli) into oral language (verbal response) accurately and fluently (Carnine, Silbert, Kame'ennui, Tarver, \& Jungjohann et al., 2006). Despite the struggling readers may be skillful in daily language use, thus, they have no problem in daily conversation, they are cognitively challenged in literacy. Learners come from all walks of life and have varying degrees of literacy abilities. The whole-language approach does not work well for learners with reading disabilities, considering the different background of each learner (Turkington \& Harris, 2006). Educators understand that there is no single best recipe for the pedagogy on reading. Even though phonics is taught in the schools, phonics alone is insufficient to nurture excellent readers because one size does not fit all.

Hitherto, research on effectiveness of oral reading intervention was heavily done in the United States learners using single-case research design (e.g., Lo, Cooke \& Starling, 2011; Tam, Heward \& Heng, 2006; Young \& Daly, 2016). To delve it deeper, comparatively, similar research design on evaluating the effectiveness of oral reading intervention in English as a second language (ESL) nation such as Malaysia is very rare (Su \& Hawkins, 2013).

Since struggling readers have problems in sounding out the printed words accurately and fluently, reading accuracy and fluency can be used to gauge the progression of the readers. Such literacy-related skills are the important factors to predict a child's reading abilities, and hence, are rational to be addressed in a reading intervention.

The primary goal of delivering reading intervention to an emerging English as a second language (ESL) reader who was struggling to master letter-sound correspondence in the present study was to provide an explicit an and systematic 
way of acquiring phonemic awareness, phonics, and fluency through repeated readings. This research is significant contributing valuable guidelines and evidences into the successful practicing oral reading intervention, particularly in light of the work of providing a one-on-one reading therapy for young learner, who is identified as facing reading difficulties at early primary school year. This research sought to answer the research question: What is the effect of a phonics-based intervention on the oral reading fluency of an ESL learner? This present study did not focus on the group average outcome, which ignores individual performance. Instead, the focus of this study was on the individual as a unit of analysis where a single-case research design was employed.

\section{METHOD}

The aim of this paper was to examine the effectiveness of a reading intervention for a primary school learner. Singlecase research design fits the purpose of this research appropriately. First, this design is practical to provide intervention to the specific participants, who are performing poorly at large-scale studies (Horner et al., 2005). Second, this design is appropriate to track and to evaluate the effects of the intervention on the behaviour at the level of a targeted participant, intensively (Byiers, Reichle \& Symons, 2012). Third, this design enables researchers to obtain feedback immediately from the participant's reading performance, instead of spending time deriving entire data and making statistical inferences to draw conclusions regarding the causal relationships between variables (Lammers \& Badia, 2004).

\section{A. Setting and Participant}

This research was conducted in a Malaysian public elementary school, the National Type (Chinese) School (hereafter SJKC), where Mandarin is the main medium of instruction, while Malay language, the national language is a compulsory subject to be learned as well (Ali et al., 2011). Learners were exposed to Highly Immersive Program (e.g. English language is used during the school assembly, every Friday is English day) and other annual English panel activities. The Primary One learners were exposed to English language during class time (six hours weekly).

The participant, henceforth known as Alex (pseudonym) was recruited through a purposive sampling method. With the referral of the Primary One classroom English language teacher, Alex was identified as needing intensive assistance to master letter-sound correspondence, participated this research after informed consent was obtained from his parents. The first author decided to include Alex in this research because he fulfilled both the inclusionary and exclusionary criteria. His ORF performance was below the 25th percentile (Hasbrouck \& Tindal, 2017) and he did not encounter with any disabilities that affected his ability to speak or hear (i.e., he was neither mute nor deaf) based on the school official record.

At the time of the research, Alex was 6 years and 6 months old. He and family lived in a local village, five minutes' drive from the school. He was nominated by his classroom English language teacher as he needed special help to master English letter-sound correspondence. Alex is an Iban (an indigenous ethnic group in Borneo). Iban language is his first language.

\section{B. Research Design and Dependent Variables}

The current research applied a single-case research design. There were three main phases throughout the study, namely baseline phase (Phase A), intervention phase (Phase B), and maintenance phase (Phase C). Word correct per minute (WCPM; Hasbrouck \& Tindal, 2017) was the unit to measure and record the dependent variable (DV) for the ORF in each session across all phases of this research.

\section{Data Collection and Procedures}

All the phases of this research were carried out in a room with minimal distraction. This room was assigned by the school administrators. The availability of Alex to the research sessions was determined by his classroom teacher.

1. Baseline Phase (Phase A)

A passage extracted from the Fitzroy Reader (Berryman \& O'Carroll, 2002) was presented to Alex. Alex was instructed to read the passage aloud. The first author measured the DV. Neither explicit cueing nor the correction feedbacks were given if the Alex did not know the word.

2. Intervention Phase (Phase B)

Each intervention session lasted approximately 45 minutes. There were two to three sessions weekly. The first author was the interventionist. Phonics, keywords preview, repeated readings, and corrective feedback were presented to the participant. By the end of each session, the DV was measured.

Using letter cards, the new sounds were introduced to the participant. The letters and the corresponding letter sounds were demonstrated to the participant explicitly. When the participant blended or segmented the sounds, immediate corrective feedback was given to the participant if there was a mistake.

The first author signaled the participant to sound out the cued letter. If there was a mistake, correction was given and the participant was guided to say it again. The first author explicitly instructed the letter-sound correspondence by demonstrating the sounds, offered discrimination exercise with other taught sounds until the participant was able to respond all the sounds correctly (Carnine et al., 2006). 
The keywords preview comprised of CVC vocabulary and high frequency vocabulary. The CVC vocabulary included the word families, which were derived from the corresponding phonics that were instructed at the beginning of the intervention session. For example, bat, cat, mat, and sat are derived from $a, b, c, m, s$, and $t$.

The high frequency vocabulary (e.g., and, on, and in) was the essential vocabulary to equip the participant's understanding the text and provided exposure to the participant on sight words.

The vocabulary was modeled by holding the phonemes for about two seconds and without pausing between the phonemes, then the participant was led to say it at usual speed (Carnine et al., 2006).

The repeated readings (RR), which is approved as a universally appropriate strategy to help young readers to achieve certain degree of fluency by reading the material (Samuels, 1997). The participant read the passage twice. After RR, the WCPM was recorded at the end of the session.

3. Maintenance Phase (Phase C)

Three passages with similar readability that contained the exact words, which Alex was exposed to throughout the Phase B, were used to assess the DV for the Phase B.

\section{Data Analysis}

Such single-case research is a quantitative research, so statistics measurement was inevitable to analyse and interpret the data. To determine the likelihood that results obtained from a sample are the same results that would have been obtained for the entire population who are struggling readers, inferential statistics are welcomed. Parametric tests are very common in determining the significance level of the results. Despite the parametric procedures are more powerful to detect the statistical significance, a nonparametric test was used in this research based on two reasons below. Firstly, the first author assumed that the data collected from the participant throughout the research are not distributing normally in the population. Secondly, all the data are frequency in scale. These reasons grossly violate the parametric test assumptions, so a nonparametric test, the Kendall tau coefficient ( $\tau$, hereafter Tau; Kendall, 1938), was considered in this research. The data collected from this research was further inspected using visual analysis, where the overlapping of data was justified using the percentage of nonoverlapping data (PND; Scruggs \& Mastropieri, 1998). Furthermore, the WCPM of the participant was compared with the updated ORF norm which was established in the United States (Hasbrouck \& Tindal, 2017). To enhance the reliability of the DV collected, the interobserver agreement (IOA) was computed.

The Tau (Kendall, 1938), a nonparametric rank correlation coefficient is appropriate to be used to compute the correlation effect size of such simple single-case research (Tarlow, 2017). Traditionally, the Tau values range from -1 to +1 ; if the Tau value is greater than 0 and closer to +1 , then there is a stronger the association between the variables; if the Tau value is less than 0 , then the opposite is true; if the Tau value $=0$, there is no relationship between the variables (Gibbons, 1993; Tarlow, 2017). If necessary, the $p$ value may be interpreted along with the Tau value using a free online calculator (Tarlow, 2016).

Subjective visual inspection (Kratochwill et al., 2010) was used to describe the trend of the baseline data, the immediacy effect of the intervention, and whether the participant return to the baseline during the maintenance. The level of the data was determined by computing the average WCPM within each phase.

The PND (Scruggs \& Mastropieri, 1998) was calculated to determine the effectiveness of the intervention by comparing the data between Phase A and Phase B. The steps involved in calculating PND were (a) divided the count of Phase B data points that did not exceed the extreme Phase A data by the total count of Phase B data; (b) converted the figure into percentage; and (c) compared the percentage to the scale as presented in Appendix A.

When the PND of an intervention is less than $50 \%$, the effectiveness of that particular intervention is ineffective. If the PND ranges between $50 \%$ and $70 \%$, the effectiveness is questionable. The intervention is considered as effective only when its PND score is between $70 \%$ and $90 \%$. If the PND is higher than $90 \%$, the intervention is very effective (Scruggs \& Mastropieri, 1998).

Furthermore, the WCPM of the participant was compared with the updated ORF norm which was established in the United States (see Appendix B; Hasbrouck \& Tindal, 2017). The Grade 1 winter fluency norm was appropriate to be compared given that there were no Malaysian norms of the similar age/grade level in ORF. Moreover, this research was carried out at the mid of the first semester of Primary One. In that ORF norm, there was no scales for the Grade 1 fall. Therefore, the Grade 1 winter fluency norm was reasonable to act as the standard for comparing this research data.

To enhance the reliability of this research, a postgraduate student served as an interobserver for this research. According to the interobserver agreement (Tam et al., 2006) formulae,

$$
\text { percentage of agreement }=(\text { number of agreements } \div \text { total of selected records }) \times 100
$$

A $38.46 \%$ of Alex's oral reading responses records were randomly selected by the interobserver to determine the WCPM. Then, the first author compared, either agreed or disagreed, both WCPM that rated by her and the interobserver with respect to the oral reading response. Using this WCPM comparing method, the equation (1) was used to compute the IOA. The first author divided the count of agreed WCPM by the total count of selected oral reading responses records, then multiplied it by 100 . The IOA was $100 \%$. 


\section{FINDINGS}

The result of Tau $=0.707, p=.021$, suggests that, the intervention was associated with the improvement in ORF; the effect was sufficient to reject the null hypothesis $(p>.05)$, hence, the association between the intervention and the WCPM scores exists. The Tau value, which was greater than 0 and closer to 1 , indicated a strong positive association between the intervention and the ORF results.

TABLE I.

ALEX'S ORF SCORES

\begin{tabular}{c|c|c|c|c|c|c|c|c|c|c|c|c|c}
\hline Phase & \multicolumn{3}{|c|}{ A } & \multicolumn{1}{c|}{ B } & \multicolumn{1}{c|}{ C } \\
\hline Session & 1 & 2 & 3 & 4 & 5 & 6 & 7 & 8 & 9 & 10 & 11 & 12 & 13 \\
\hline WCPM & 0 & 0 & 0 & 40 & 39 & 37 & 12 & 11 & 21 & 13 & 6 & 22 & 18 \\
\hline
\end{tabular}

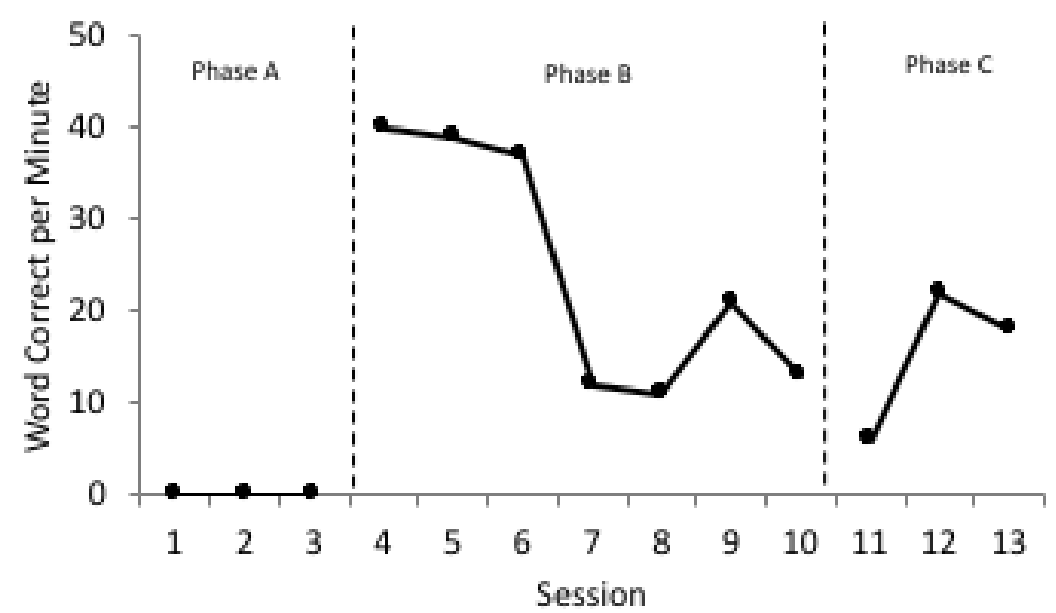

Figure 1. The result of oral reading fluency in term of word correct per minute (WCPM) of Alex across three phases, namely Phase A, Phase B, and Phase C, which are equivalent as baseline, intervention, and maintenance, respectively.

Table I charts Alex's ORF scores in terms of WCPM for each session across three phases. In the phase A, there were three baseline sessions. Alex was unable to decode all the words presented in three different ORF passages. The first author observed that he read the text by saying all the letter names loudly, clearly, correctly and confidently. All the zero scores alarmed the first author that such floor effect would remain unimproved, if left unaddressed. Hence, the first author decided to impose the intervention.

Upon the implementation of intervention in the Phase B, Alex began to able blend the sounds to form word when reading! There were seven intervention sessions in the Phase B and inevitably, he scored lower in terms of WCPM whenever he was introduced to a new and less familiar ORF passages. There were altogether four ORF passages exposed to Alex. The Phase B was forced to call to an end due to the consecutive ad-hoc national and state public holidays as a result of the general election and followed by the school first semester examinations.

After two weeks of the final session of the Phase $\mathrm{C}$ and right before the one-month school holiday began, the first author revisited Alex to conduct the Phase C sessions. There were three maintenance sessions to follow up Alex's ORF. It was inspiring that Alex did not 'unlearn' the decoding skills and managed to read the ORF passages without guidance and feedbacks.

Fig. 1 illustrates a clear pattern that Alex showed immediate improvement once the intervention was imposed at the initial of Phase B. Despite the decline in performance in term of WCPM, Alex did not return to the baseline (thus, the floor effect as in the Phase A) when the intervention was withdrawn in the Phase C.

TABLE II.

\begin{tabular}{cc} 
THE LEVEL OF PARTICIPANT IN TERMS OF WCPM ACROSS PHASES \\
\hline Phase & Level (WCPM) \\
\hline A & 0 \\
B & 24.7 \\
C & 15.3 \\
\hline
\end{tabular}

Table II shows the level of ORF of Alex across three phases. In the phase A, the average ORF score of Alex is 0 , while Alex managed to achieve 24.7 WCPM in the Phase B. It is exciting to witness that the level of the first three intervention sessions in the Phase B of Alex is 38.7 (refer to Table I), which demonstrates a rapid improvement from the floor effect to such rocket high record. The WCPM level drops to 15.3 in the Phase C. It is compelling to notice that the level of the final three intervention sessions in the Phase B is 15.0 (refer to Table I) and it does not have high variability when comparing to the level of Phase C. In addition, the Phase $\mathrm{C}$ level is significantly higher than the Phase A floor effect. 
The effect size of this research is determined by the PND. When comparing the data between the Phase A and Phase $\mathrm{B}$, the PND $=100 \%$, which means the intervention is very effective (see Appendix A).

The level of ORF scores in the Table II was compared with the fluency norms (Hasbrouck \& Tindal, 2017; see Appendix B). Initially, Alex's WCPM falls under the $10^{\text {th }}$ percentile in the Phase A, where there was neither guidance nor intervention. After the intervention was carried out in the Phase B, the level of WCPM reaches between the $50^{\text {th }}$ and the $75^{\text {th }}$ percentile. Towards the end of the intervention, even though Alex still had not reach the $90^{\text {th }}$ percentile, he was approaching the $25^{\text {th }}$ percentile during the follow-up in the Phase C.

\section{DISCUSSION}

This research is examined the effects of conducting an intervention to improve the oral reading skills of a learner who struggled with reading. Being an ESL learner, exposure to the letters of the alphabet (i.e., names and sounds) provided the participant with the letter-sound correspondent necessary to boost his ability to blend simple CVC sounds needed to provide him with the foundation to decode and read fluently. The student made improvements after receiving one-to-one intervention which lasted 45 minutes for seven sessions. This study shows that by focusing on a single case as a unit of analysis using single-case research design provides researchers and practitioners with the tools to focus on individualized intervention. This study is not without limitation. Further investigations must be carried out on participants with similar baseline characteristics; the maintenance phase must be revisited to ensure that over the next 6 12 months, the participant continues to maintain his performance. To date, there was no any intervention studies that was using the Fitzroy Readers as main material, to compare and contrast the findings. Future studies should focus on the effectiveness of Fitzroy Readers as an intervention material for more learners with other learning disabilities.

\section{APPENDIX A. EFFECTIVENESS SCALE FOR PND ${ }^{1}$}

\begin{tabular}{cc}
\hline PND Score (\%) & Effectiveness \\
\hline$<50$ & Ineffective \\
$\geq 50$ and $>70$ & Questionable \\
$\geq 70$ and $>90$ & Effective \\
$\geq 90$ & Very Effective \\
\hline
\end{tabular}

\section{APPENDIX B. GRADE 1 WINTER FLUENCY NORM ${ }^{2}$}

\begin{tabular}{cccccc}
\hline Percentile & 10 & 25 & 50 & 75 & 90 \\
\hline WCPM & 9 & 16 & 29 & 59 & 97 \\
\hline
\end{tabular}

\section{ACKNOWLEDGMENTS}

The first author would like to bid thank you to the officers of the Educational Planning and Research Division at the Ministry of Education Malaysia, the officers of the Management Service and Development Sector at the Sarawak State Education Department, the school principal, teachers, parents and participant who had offered their best co-operation for this research. The first author thanks Professor Edward J. Daly III and Professor Thomas E. Scruggs for guidance.

\section{REFFERENCES}

[1] Ali, N. L., Hamid, M. O. \& Moni, K. (2011). English in primary education in Malaysia: Policies, outcomes and stakeholders' lived experiences. Current Issues in Language Planning 12.2, 147-166.

[2] Byiers, B. J., Reichle, J. \& Symons, F. J. (2012). Single-subject experimental design for evidence-based practice. American Journal of Speech-Language Pathology 21.4, 397-414.

[3] Carnine, D. W., Silbert, J., Kame'ennui, E. J., Tarver, S. G. \& Jungjohann, K. (2006). Teaching struggling and at-risk readers: A direct instruction approach. Upper Saddle River: Pearson.

[4] Chitravelu, N., Sithamparam, S., \& Teh, S. C. (2005). ELT methodology: Principles and practice (2nd ed.). Shah Alam: Oxford Fajar.

[5] Gibbons, J. D. (1993). Nonparametric measures of association. Series: Quantitative applications in the social sciences. Newbury Park: Sage Publications.

[6] Hasbrouck, J. \& Tindal, G. (2017). An update to compiled ORF norms (Technical Report No. 1702). Eugene, OR: Behavioral Research and Teaching, University of Oregon.

[7] Horner, R. H., Carr, E. G., Halle, J., McGee, G., Odom, S. \& Wolery, M. (2005). The use of single-subject research to identify evidence-based practice in special education. Exceptional Children 71.2, 165-179.

[8] Kendall, M. G. (1938). A measure of rank correlation. Biometrika 30, 81-93.

[9] Khor, C. P., Low, H. M., \& Lee, L. W. (2014). Relationship between oral reading fluency and reading comprehension among ESL students. Journal of Language Studies, 14.3, 19-32. 
[10] Kratochwill, T. R., Hitchcock, J., Horner, R. H., Levin, J. R., Odom, S. L., Rindskopf, D. M. \& Shadish, W. R. (2010). Singlecase design technical documentation. Retrieved from What Works Clearinghouse. https://ies.ed.gov/ncee/wwc/Docs/ReferenceResources/wwc_scd.pdf (accessed 6/11/2018).

[11] Lammers, W. J. \& Badia, P. (2005). Fundamentals of behavioral research. Belmont: Thomson/Wadsworth.

[12] Lo, Y., Cooke, N. L. \& Starling, A. L. P. (2011). Using a repeated reading program to improve generalization of oral reading fluency. Education and Treatment of Children, 34.1, 115-140.

[13] Pillai, A. D. R., \& Paramasivam, S. (2014). Miscue analysis of oral reading among non-proficient Malaysian ESL learners. Journal of English and Literature 2.2, 179-185.

[14] Samuels, S. J. (1997). The method of repeated readings. The reading teacher 50.5, 376-381.

[15] Scruggs, T. E., \& Mastropieri, M. A. (1998). Synthesizing single-subject research: Issues and applications. Behavior modification 22.3, 221-242.

[16] Su, S. C. K., \& Hawkins, J. (2013). THRASS phonics: A case study of Thomas as an emerging reader in English. The English Teacher 42, 52-73.

[17] Tam, K. Y. B., Heward, W. L. \& Heng, M. A. (2006). A reading instruction intervention program for English-language learners who are struggling readers. The Journal of Special Education 40.2, 79-93.

[18] Tarlow, K. R. (2016). Baseline Corrected Tau Calculator. Retrieved from http://www.ktarlow.com/stats/tau (accessed $10 / 12 / 2018)$.

[19] Tarlow, K. R. (2017). An improved rank correlation effect size statistic for single-case designs: Baseline Corrected Tau. Behavior Modification 41.4, 427-467.

[20] Turkington, C. \& Harris, J. R. (2006). The A to Z of learning disabilities. New York: Checkmark Books.

[21] Young, N. D. \& Daly, E. J. III. (2016). Effects of performance criteria during reading instruction on generalized oral reading fluency. Behavioral Interventions 31, 291-299.

Hui Hong Gan received her bachelor degree in Cognitive Sciences in year 2015 from University Malaysia Sarawak, Malaysia. She is finishing her master degree in learning science by research on the oral reading intervention for children.

Julia Ai Cheng Lee gained her PhD in special education from Florida State University in year 2012. She currently is a senior lecturer cum deputy dean (research and postgraduate) at the Faculty of Cognitive Sciences and Human Development, University Malaysia Sarawak. Dr. Lee's areas of research interest are early childhood education, including language and literacy intervention with the use of digital technologies, and reading and spelling development and difficulties.

Kartini Abdul Ghani obtained her PhD in psychology from The University of York in year 2016. She is a lecturer at the Faculty of Cognitive Sciences and Human Development, and she holds a position of deputy dean (learning advancement) at the Centre of Applied Learning and Multimedia, University Malaysia Sarawak. 